\title{
STATE REGULATION OF FRANCHISING IN THE EU MEMBER COUNTRIES
}

\author{
Solomiya OHINOK ${ }^{1}$, \\ Ivan Franko National University of Lviv, Ukraine
}

\begin{abstract}
In despite of extensive research of franchising in the scientific community, there are a lot of unresolved issues relating to franchising, in particular its regulation at the national level and the level of the European Union that is why the purpose of the paper is to summarise and present the difference between state regulation of franchising in the EU member states and to research the basic principles of state regulation of franchising in the EU also to analyze legislation of the franchise relationship. Methodology. The survey is based on a comparison of data from all EU member countries and analisis of the legal framework of each country in particular and in general EU legislation. The article is devoted to a detailed analysis of main features of the franchise business in Europe. The mechanism of implementation of franchise relations between EU member states are studied. Government regulation of franchising in the EU member states are investigated. The rate of growth of franchising in Europe are analized. Results. By comparing different state laws and regulations of franchising we have identified the most effective and productive. We divided counties into two groups due to their regulation of franchising: countries which do not have a special government regulation of franchising; the countries which have state regulation of franchising; countries which have government regulation of franchising and it is governed by EU law, countries in which regulation is carried out in accordance with EU law. Thus, results of the survey showed that government regulation of franchising, as well as its regulation at the level of EU institutions have a positive impact on the development of franchising relationships. Practical implications of the results of the paper will help to develop well known network of franchise bussiness without legislative interference. Value/originality. It is first time we have grouped countries due to the main aspects of state regulation of franchising.
\end{abstract}

Key words: franchising, european business, international economic relations, european market, state regulation.

JEL Classification: M20, F5, K29

\section{1. Введение}

Франчайзинг признан в мире, как наиболее прогрессивная форма ведения бизнеса (Yalovoy, G., 2013). Привлекательность франчайзинга опреАеляется, прежАе всего, его прозрачностью и комплексным характером. Такая стратегия ведения бизнеса предоставмяет большие перспективы, поскольку позволяет привлекать иностранные инвестиции из различных стран Аля развития одной отрасли, а также внеАрять высокие станАарты. Государственное регулирование франчайзинга в странах ЕС Аостаточно разнообразное и мало исслеАованно, поэтому требует Аальнейшего анализа и рассмотрения, что Ааст новые перспективы Аля его развития.

Учитывая большую популярность франчайзинга в Европе и мире, он является Аостаточно исследуемой темой. СреАи ученых, занимавшихся анализом франчайзинга, отметим таких С. Сосна, Е. Васильева, А. Городова, Р. Гамельтон, И. Аахно, А. ХайфилА, М. Мендельсон, А. СтэнфорА, Б. Смит, Н. Широбо- кова, В. Шкромада, А. Бамде, Е. Кошелев, В. Аенисюк,

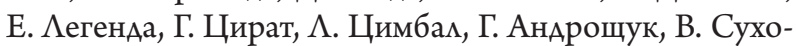
ватый, В. Аяшенко. Несмотря на широкие исследования франчайзинга в научных кругах, существует достаточно много нерешенных вопросов, касающихся сферы франчайзинга, в частности его регулирования на государственном уровне в странах-чиенах ЕС.

\section{2. Ромь франчайзинга в Европе}

Высокая попумярность и значительная распространенность франчайзинга определяется тем, что он преАоставцяет реальные возможности Аля развития сети сбыта товаров как на национальных рынках, так и на зарубежных, привлекая относительно небольшие среАства, а главное за небольшой промежуток времени.

Роль франчайзинга в Европе растет с кажАым годом, веАь на базе ЕАиного европейского рынка страны-чиены ЕС получили значительные преимущества, связанные с активизацией межАународного производства и стимулирования деятельности крупных и малых компаний.

\footnotetext{
Corresponding author

${ }^{1}$ Department of International Economic Relations, Ivan Franko National University of Lviv, Ukraine

E-mail: ohinok.solomiya@gmail.com
} 


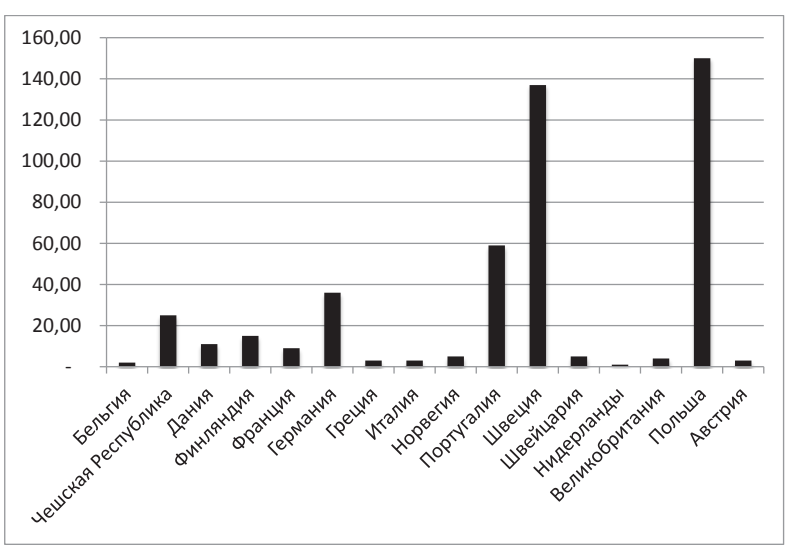

Источник: Составлено автором на основе данных (The European Franchise Federation, 2015)

Рис. 1. Темпы роста франчайзинга в странах-чиенах ЕC

Распространению франчайзинга как инструмента увеличения количества сетей сбыта товаров способствует обретения страной членства в ЕС, веАь именно так переА национацьными фирмами открываются широкие возможности вхождения на крупные и небольшие иностранные рынки.

Сегодня европейский франчайзинг развивается постепенно и непрерывно, по данным МежАународной Федерации Франчайзинга европейские франчайзеры занимали $31 \%$ мирового рынка в 2013 году (The European Franchise Federation, 2015).

Наиболее привлекательными Аля развития франчайзинга являются страны Центральной и Юго-Восточной Европы, среди них Польша, Чехия и Венгрия. Интересно, что среди стран Центральной и Восточной Европы милером по количеству франчайзинговых бренаов есть именно Польша. После вступления Помьши в Европейский Союз ее возможности по развитию собственных преАприятий с помощью франчайзинга стали значительно больше. Вместе со вступлением в ЕС переА польскими франчайзинговым сетями открылись широкие возможности выхода на зарубежные рынки и сбыта собственной продукции на территории общего рынка ("Report on franchising in Poland," 2015).

Распространению франчайзинга в Польше, Болгарии, Румынии, Венгрии и Чешской Республике способствует миберализация их экономик, в связи с вступлением в ЕС и интеграция в организованную коммерческую систему европейского рынка. Эти страны явцяются очень популярными Аля иностранных инвесторов в связи с высоко-квалифицированной рабочей силой, существенным ростом рыночного спроса и приемлемыми ценами на рекламу и неАвижимость. На рынках стран Центральной и Юго-Восточной Европы существует большая конкуренция межАу американскими и западно-европейскими сетями, так как первые обладают широко-известными марками и хорошей репутацией, а вторые хорошо знакомы с рынком и потребительским спросом.

\section{3. Государственное регумирование франчайзинга}

ОАнако рынок франчайзинга в некоторых странах явмяется весьма ограниченным, прежде всего это касается нехватки внутреннего капитала и отсутствия адекватной законодательной базы. Существует ряд стран, которые имеют совершенное государственное регулирование франчайзинговой Аеятельности, но большинство стран Европы его не имеют или оно уже Аолгое время находится на стадии разработки. Предлагаем рассмотреть это более подробно. Разделим страны на следующие группы:

- страны, которые не имеют отдельного государственного регулирования франчайзинга;

- страны, в которых франчайзинг регулируется на государственном уровне;

- страны, которые имеют государственное регулирование франчайзинга, а также он регулируется правом ЕС.

- страны, в которых государственное регулирование осуществляется в соответствии с правом ЕС.

К первой группе стран относятся: Португалия, Швейцария, Чехия и Греция. ОАнако, осуществцять франчайзинговые отношения их участники Аолжны Аействовать в соответствии с нормами Гражданского кодекса, законов об интемлектуамьной собственности и намогообложения.

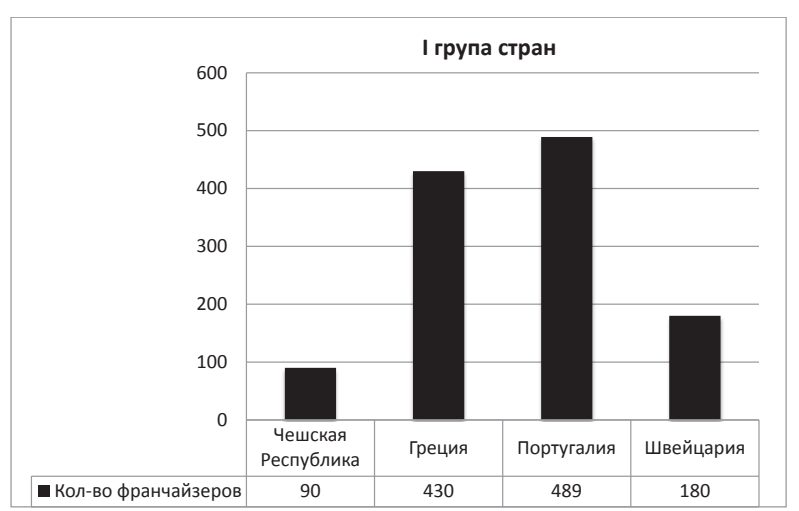

Источник-составлено автором на основе данных (Тор 500 Franchises in Europe, 2015)

Рис. 2. Страны, не имеющие отаемьного госуАарственного регумирования франчайзинга

Ко второй группе относятся Великобритания, Бельгия, Италия и Норвегия. В Великобритании франчайзинговые отношения регулируются Аоговорным правом. В Бельгии франчайзинг регулируется в соответствии с Государственным Актом, 2005 года (the 2005 Disclosure Act). В Италии с 2004 года существует отАельный закон, которым регулируются франчайзинговые отношения, а также указам Министерства экономического развития Италии, с 2005 года. В Норвегии регулирования франчайзинга осуществляется антимонопольной правовой базой. ОАнако, рассматривая госуАарственное регулирование во второй группе стран, следует отметить, что отдельным законодательным 
актом государственное регулирование франчайзинга осуществляется только в Италии, а в Бельгии и Норвегии оно осуществцяется в части определенного нормативного акта или закона.

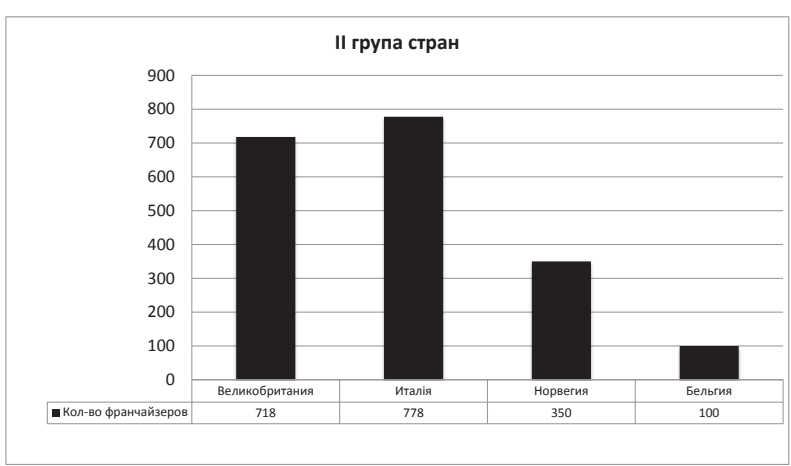

Источник-составлено автором на основе данньх (Тор 500 Franchises in Europe, 2015)

Рис. 3. Страны, в которых франчайзинг регумируется на государственном уровне

К третьей группе стран относятся Австрия, Франция, Германия и Италия. Государственное регулирование франчайзинга в Австрии осуществмяется в части национальной антимонопольной базы, а также в соответствии с правом ЕС - Регламентом Комиссии (ЕС) № 2790/1999 «О применении статьи 81(3) Аоговора к категориям вертикальных соглашений и согласованных Аействий $\gg$ ИС 330/2010 в Германии регулируется конкурентным правом и EC Reg. 330/2010 (Commission Regulation (EC) N 2790/1999 of 22 December 1999 on the application of Article 81(3) of the Treaty to categories of vertical agreements and concerted practices,1999), (Burnett, 2004). Во Франции франчайзинговые отношения также регулируются EC Reg. 330/2010, оАнако на национацьном уровне существует отАельный законодательный акт (Loi DOUBIN), которым государство регулирует Аанный виА экономической деятельности. В Швеции государственном регулировании франчай-

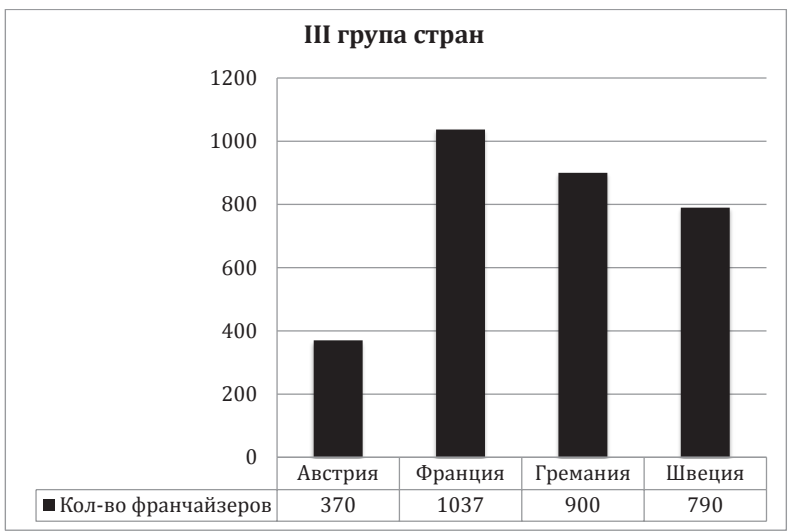

Источник-составлено автором на основе данных (Тор 500 Franchises in Europe, 2015)

Рис. 4. Страны, имеющие государственное регудирование франчайзинга, а также он регумируется правом ЕС зинга осуществляется на обоих уровнях, на национальном уровне с 2006 года (SFS 2006: 484) и на уровне ЕС c 2010 (EU Reg. 330/2010).

К четвертой группе стран отнесем Финияндию, Аанию, Нидерланды и Польшу. Все эти четыре страны имплементировали EC Reg. 330/2010 и осуществмяют госуАарственное регулирование франчайзинга в соответствии с нормами и положениями этого документа. На национальном уровне ни у Финмяндии, ни Аании, ни Нидерландов, ни Польшы нет специального законодательного акта Амя урегулирования франчайзинговых отношений.

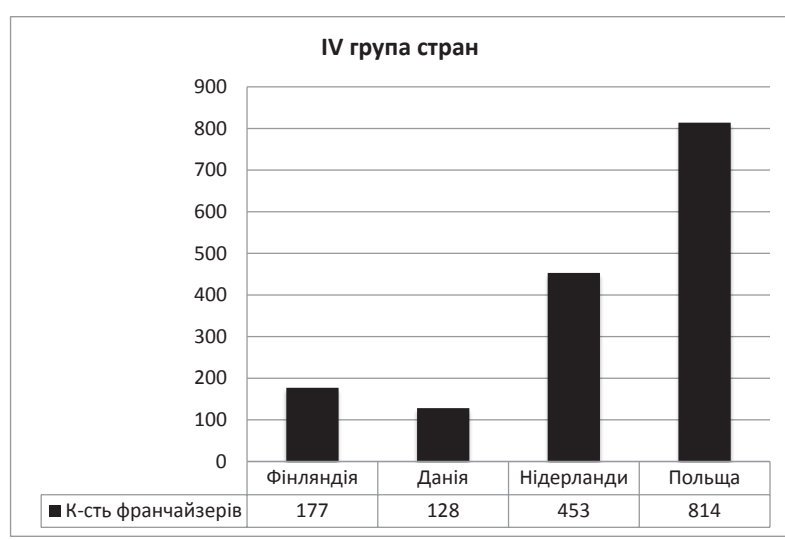

Источник-составлено автором на основе данных (Тор 500 Franchises in Europe, 2015)

Рис. 5. Страны, в которых государственное регумирование осуществмяется в соответствии с правом ЕС

По нашему мнению, следует обратить внимание, на то, что франчайзинг явцяется экономической Аеятельностью, поэтому его государственное регулирование осуществляется в соответствии с нормами, которые закреплены в таких законотворческих актах как ГражАанский Кодекс, Закон о праве на интеммектуальную собственность, Налоговый Кодекс и ряд Аругих законов, регулирующих экономическую Аеятельность в кажАой стране.

\section{4. Выводы}

Анализируя выше приведенный материац, можем сделать вывоА, что страны, которые относятся к II, III и IV группы стран имеют значительно более высокие темпы роста количества франчайзеров чем те, что относятся к первой. Итак, государственное регумирование франчайзинга, а также его регулирования на уровне институтов Европейского Союза положительно влияют на развитие франчайзинговых отношений. Также стоит обратить внимание на III группу стран, в которых есть как государственное регулирование франчайзинга и так же он регулируется правом Европейского Союза, поскольку они явцяются ярким примером того, что чем больше урегулирован франчайзинг как экономической деятельности, тем позитивнее это вАияет на его рост и развитие. 


\section{References}

Report on franchising in Poland 2015 - Thousand ideas for business in 2015. (2015). Retrieved from http://franchise.org.pl/report-on-franchising-in-poland

Yalovoy, G. (2013) Prospects for the development of commercial concession (franchise) in Ukraine - Kiev, Taras Shevchenko National University of Kyiv, 203 p.

Burnett, R. (2004) Law of International Business Transactions. 3rd ed. - Sydney, 329 p.

Commission Regulation (EC) N 2790/1999 of 22 December 1999 on the application of Article 81(3) of the Treaty to categories of vertical agreements and concerted practices,1999. Vol. 42, L 336. - P. 21-25.

The European Franchise Federation. (2015). Retrieved from http://www.eff-franchise.com

Top 500 Franchises in Europe. (2015). - Retrieved from http://www.franchisedirect.co.uk/top500/

\section{Соломия ОГИНОК}

\section{ГОСУДАРСТВЕННОЕ РЕГУЛИРОВАНИЕ ФРАНЧАЙЗИНГА В СТРАНАХ ЕС}

Аннотация. В несмотря на обширные исследования франчайзинга в научном сообществе, есть много нерешенных вопросов, касающихся франчайзинга, в частности, его регулирование на национальном уровне и на уровне Европейского Союза, поэтому целью данной работы является обобщение и представление разницы между государственным регулированием франчайзинга в странах-членах ЕС и исследование основных принципов государственного регулирования франчайзинга в ЕС также анализ законодательства франчайзингових отношений. Статья посвящена детальному анализу основных особенностей франчайзинга в Европе. Методика. Исследование основано на сравнении данных из всех стран-членов ЕС и анализ правовой системы каждой страны в частности и в целом законодательства ЕС. Изучен механизм реализации франчайзинговых отношений между государствами-членами ЕС, так же исследовано государственное регулирование франчайзинга в странах-членах ЕС. Проанализированы темпы роста франчайзинга в Европе. Сравнивая различные государственные законы и правила франчайзинга мы определили наиболее эффективные и продуктивные. Результаты. Мы разделили страны ЕС на группы в согласно регулирования франчайзинга: страны, которые не имеют специального государственного регулирования франчайзинга; страны, которые имеют государственное регулирование франчайзинга; страны, которые имеют государственное регулирование франчайзинга и он регулируется законом ЕС, страны, в которых регулирование осуществляется в соответствии с законодательством ЕС. Таким образом, результаты исследования показали, что государственное регулирование франчайзинга, а также его регулирование на уровне институтов ЕС оказывает положительное влияние на развитие отношений франчайзинга. Практические последствия результатов работы поможет развить хорошо известную сеть франчайзинга без законодательных препятствий. Значение/оригинальность. Впервые мы сгруппировали страны в соответствие с основными аспектами государственного регулирования франчайзинга. 